\title{
DEVELOPMENT OF NUMERICAL PLATFORM FOR AIRCRAFT SYSTEMS SIMULATION (DRAFT)
}

\author{
Rianto A. Sasongko ${ }^{1, *}$, Yorgi A. Ndaomanu ${ }^{1}$, Yazdi I. Jenie ${ }^{1}$, M. Luthfi I. Nurhakin ${ }^{1}$, M. Rafi \\ Hadytama, Yusuf K. Asalani ${ }^{1}$
}

\begin{abstract}
This paper discusses the development of a numerical simulation platform that can be used for representing the principal works of aircraft systems. The platform consists of some parts each of which is intended to replicate the operation of a system implemented in a modern aircraft, such as hydraulic line, electrical system, landing gear system, control system, etc. The platform is intended to be a tool for modeling and analyzing the operation and performance of certain systems configuration. To some extend the platform can be viewed as a virtual Iron Bird System. Iron Bird is a term representing a platform for simulating the works of aircraft systems using real components, which is very important for aircraft system development. At this stage, the numerical platform will only involve some sub-systems, namely main hydraulic line, control surface actuation, landing gear, and control system. These sub-systems are chosen to be the basis for further development where other sub-systems will be added and integrated to the platform.
\end{abstract}

Keywords-Aircraft System, Numerical Simulation, System Analysis

\section{INTRODUCTION}

Modern aircraft comprises of many subsystems that form the whole aircraft system supporting the operation of aircraft. As the aircraft technology develops, many new devices and equipments are applied for various reasons, such as those related to aircraft operation, performance, safety, etc. The implementation of these systems introduces complexity in design of aircraft and its systems [1-2].

\footnotetext{
${ }^{1}$ Aerospace Enginnering, Faculty of Mechanical and Aerospace Engineering, InstitutTeknologi BandungJl. Ganesha 10, Bandung 40132, Indonesia.e-mai : sasongko@ae.itb.ac.id
}

Usually, an Iron Bird simulator consists of real system which is implemented on the corresponding aircraft. Hence, by using this platform those systems can be simulated and tweaked or reconfigured, such that the desired system characteristics and performance can be achieved [3]. To anticipate the complexity and difficulty in aircraft system development phases, many devices are built that can be utilized as design tools, for example an iron bird system. Iron bird is a term referenced to a set of aircraft systems/equipments which are used as simulation platform, where the works and operation of systems on real aircraft can be replicated.



Fig 1. F-8C Iron Bird Simulator

Iron bird simulator has become a key element in aircraft design process, especially in designing the system configuration of the aircraft. 
An Iron Bird simulator can be consists of all the system implemented on particular aircraft, namely the control system, hydraulic system, pneumatic system, landing gear, fuel system, etc. Since it uses real components that are applied on the aircraft, an Iron bird simulator is very expensive equipments [4-5].

In this research, a simulator platform is developed based on numerical computation, which can simulate some systems applied on an aircraft. To some extent, this platform is intended to emulate the function of an iron bird system, but in a down-scaled capacity and complexity. This virtual platform is intended as a preliminary tool that can be used for studying, evaluating, and designing aircraft system configuration in earlier stage of aircraft development or studies.

At this stage, a numerical platform is developed which consists of only some simplified subsystems on an aircraft, namely the hydraulic line, control system, control surface actuation, and landing gear systems. Further, it is aimed to develop a more complete and complex virtual system based on this platform. Some results related to the development of this platform will be presented in this paper.

This paper will be presented in the following outline. The second section will discuss the main architecture of the developed platform, while in the second section some subsystems that are included in the platform will be described. The current stage of development of each subsystem will be presented in the third section, followed by some simulation results of the developed subsystem which are discussed in Section Four. Some conclusions and remarks regarding the development and results of the activities will be presented in the fifth section.

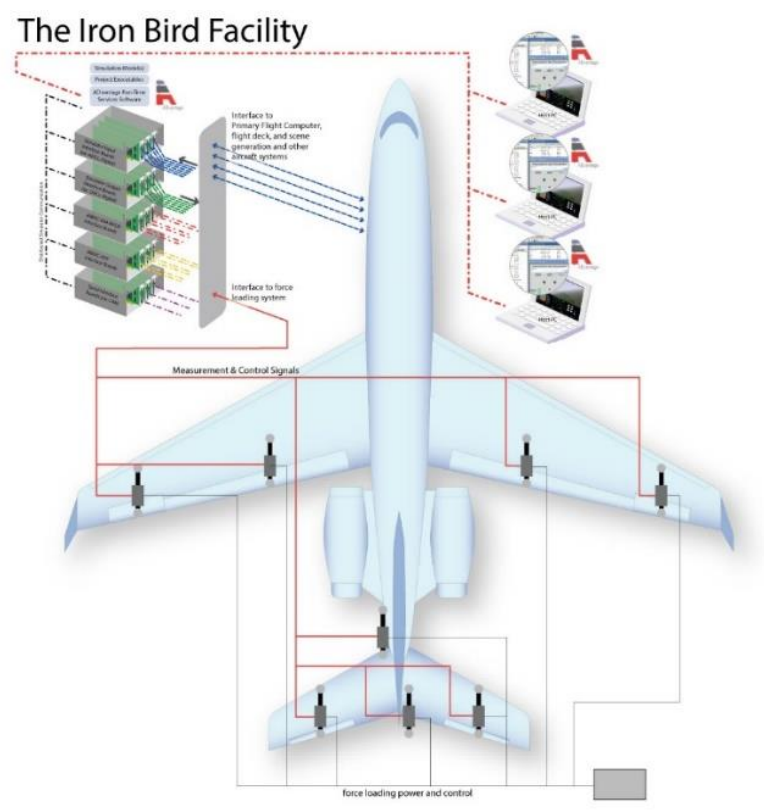

Fig 2. Iron Bird Simulator Example [6-8]

\section{Virtual SubSystems}

As explained previously, at this stage it is aimed to first build a basis for more complete and complex virtual simulator, hence only some subsystems are developed, namely the hydraulic line, control system, control actuation, and landing gear subsystems.

\section{A. Hydraulic Line}

A virtual aircraft hydraulic line is developed as basis for building more realistic aircraft hydraulic lines and systems in the next stage of this work. The basis configuration is adopted form a generic or simple hydraulic line of a particular aircraft. 


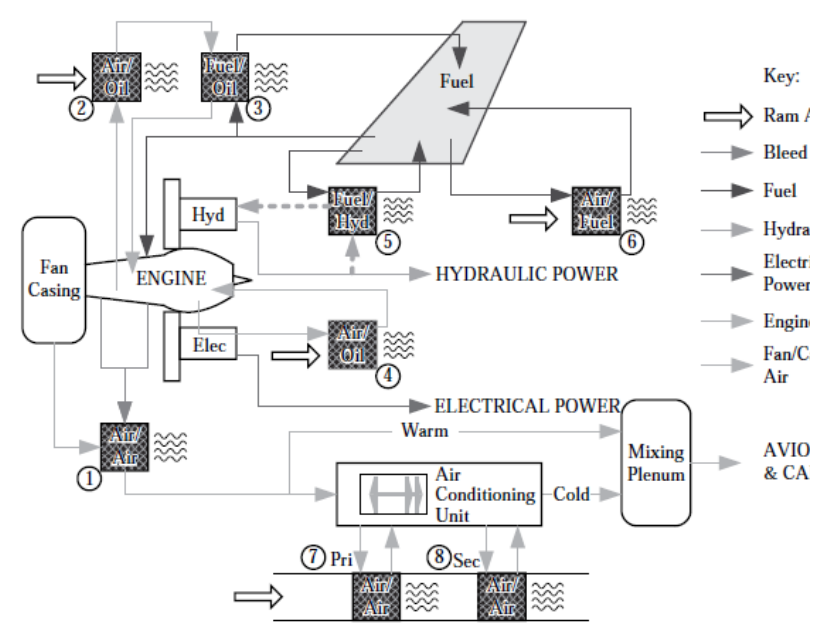

Fig 3. Hydraulic Line model [8]

It is intended to first simulate the principle work/operation of hydraulic lines, which further will be developed to be the main basis of various model of hydraulic based device on an aircraft.

\section{B. Landing Gear System}

Landing gear system is the next subsystem to be included on the developed platform. As known, a landing gear system involves multi-domain subsystems, such as hydraulic actuator, electrical system, and mechanical linkage. The modeling of this system includes the formation of mechanical kinematics and dynamics model, and in the next step will also include the hydraulic actuation model, which will be linked to the hydraulic line model.

\section{Control Device Actuation}

Similar to landing gear system, control device actuation systems, such as aileron, rudder, elevator, flap, consist of multidomain subsystems, namely the mechanical linkage, hydraulic actuators, and electrical sensors. Hence the modeling of these systems will involve aspects related the work principles and characteristic of hydraulic, mechanical, and electrical systems. Further these system will also be linked to the hydraulic line model.

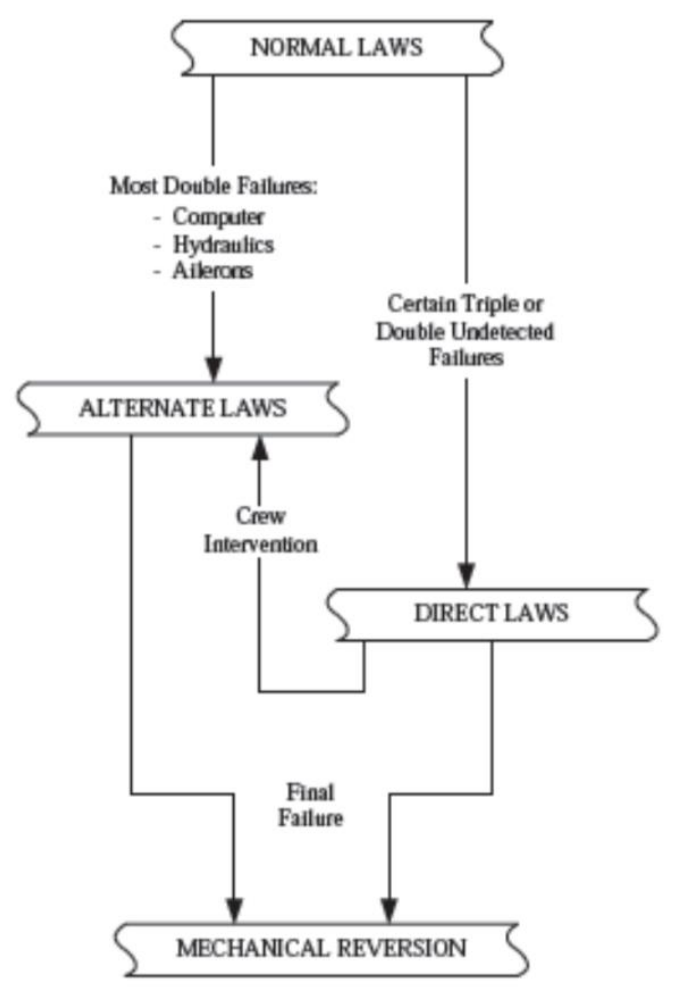

Fig 4. Flight Mode Example

\section{Control System}

The fourth system that will be included in the developed platform is the control system. Here, it is focused on the modeling of the implementation of flight control using fly by wire platform. The principle of flight control mode, flight control redundancy will be modeled. It is aimed to be able to simulate the change of flight mode, some redundancy and back-up procedures 
implemented in fly by wire system under some scenario flight condition.

\section{PlatForm DEVELOPMENT}

At this stage, some systems described previously have been developed, either their virtual representation or their basic operation formulation.

\section{A. Hydraulic Line Model}

A simple hydraulic model line is constructed as a basis for further model development. The hydraulic line of ATR 72-600 aircraft is adopted and simplified for developing the model. The model will include some components such as reservoir, hydraulic pumps, and valves. At this stage, the hydraulic system quantitative representations (mathematical models) are not used yet, but rather they are represented as a combination of rules and logics constructing the principle works of the system [9-10].

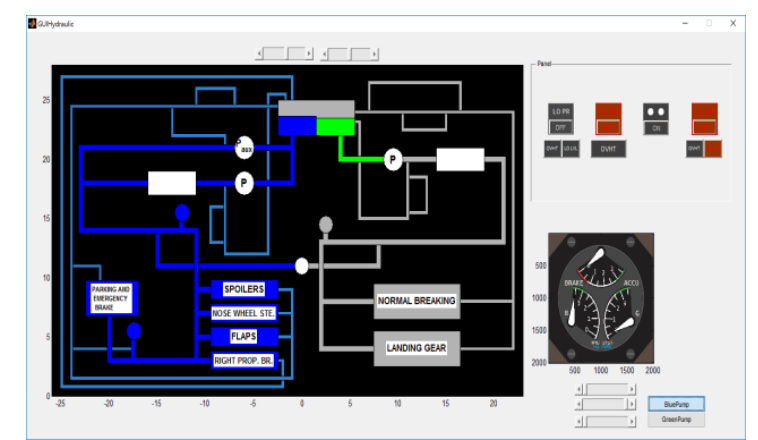

Fig 5. Example of developed interface of hydraulic line model

\section{B. Landing gear}

The kinematic model of a simple landing gear mechanism is already developed. The model is formed by considering a 3 linkage kinematic formulation, which is then is also modeled using Sim-Mechanics application. The visualization of the mechanism is already developed and linked to the SimMechanics model.
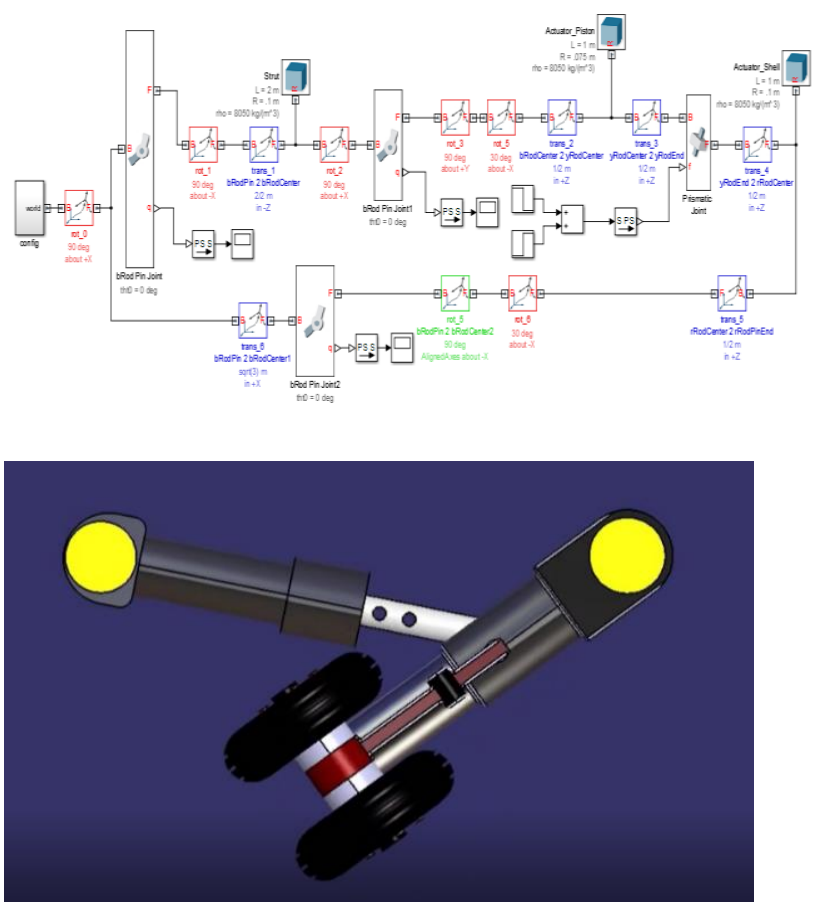

Fig 6. Landing Gear Kinematic model (above) and visualization (below)

\section{Control System}

A model of a rule/logic implemented in an element of a fly by wire system is already constructed. The model represents the principle of work of a link from control reference input (from pilot manipulators), control signal generator, actuator reference generator, and the actuator. The model can simulate some condition when predefined failures occur on the system, and how the back-up components handle the situations. 


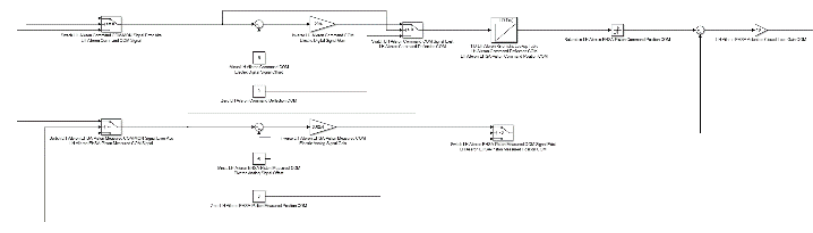

Fig 7.Control System Component Model

\section{Simulation RESUltS}

Some models of the developed subsystems have been simulated for some predefined scenarios. Some results are presented here. One of the simulations that have been carried out is the one related to the landing gear kinematic model. The mathematical model of the kinematic system is implemented SIMULINK and simulated [11]. The SIMULINK model is depicted in the Fig. 8 below.

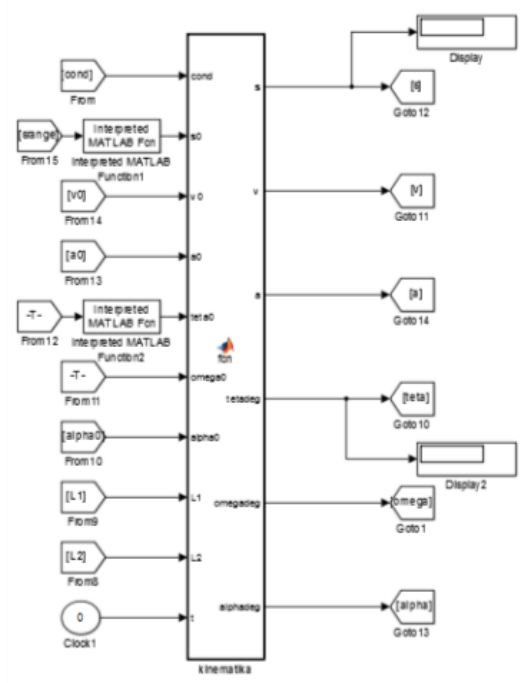

Fig 8. SIMULINK model of the landing gear kinematic

The parameter setting of the simulation is listed in the following table.
Fig 9. Simulated Linkage Mechanism

Table 1. Simulation Parameters

\begin{tabular}{|c|c|c|}
\hline Parameters & Value & Unit \\
\hline Kondisi & $\begin{array}{l}1-\text { constant } a \\
2-\text { constant } \alpha^{*}\end{array}$ & - \\
\hline $\begin{array}{l}\text { [s_0; } \\
\text { s_max] }\end{array}$ & {$[1 ; 5]$} & $\mathrm{m}$ \\
\hline $\mathrm{v} \_0$ & 0,5 & $\mathrm{~m} / \mathrm{s}$ \\
\hline $\mathrm{A}$ & 0 & $\mathrm{~m} / \mathrm{s}^{2}$ \\
\hline $\begin{array}{l}{[\theta \quad 0 ;} \\
\theta \max ]\end{array}$ & {$[0 ; 90]$} & deg \\
\hline$\omega_{-}^{-} 0$ & $2 *$ & $\mathrm{deg} / \mathrm{s}$ \\
\hline $\mathrm{A}^{-}$ & $0^{*}$ & $\mathrm{deg} / \mathrm{s}^{2}$ \\
\hline L1 & 4 & $\mathrm{~m}$ \\
\hline L2 & 3 & $\mathrm{~m}$ \\
\hline
\end{tabular}

The results of the simulation show the response of the variables of the model representing the motion of the landing gear mechanism. The results are showed in figures below. 



Fig 10.Linkage Translation Variable response
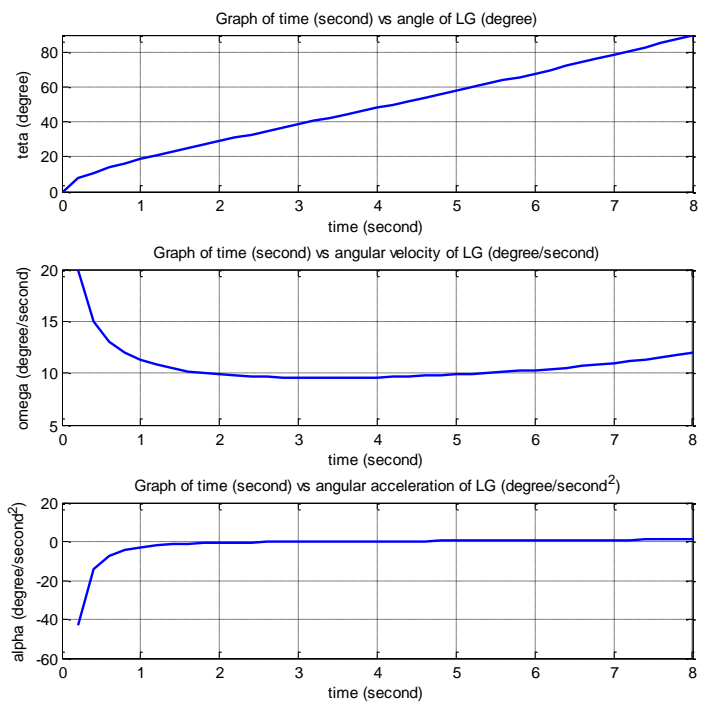

Fig 11. Linkage Angular Variable response

It can be seen that for the modeled mechanism, the quantitative kinematic representation (mathematical model) can produce the response of system variable representing realistic motions of the landing gear. This model will be improved in further development.

\section{CONCLUSIONS AND REMARKS}

The initial stage development of a numerical platform for simulating some aircraft systems has been carried out. Several models of hydraulic line, landing gear kinematics, and control system rule/logic are already constructed. Simulation of the landing gear model produces quite good results, representing a realistic motion of the landing gear system. Further improvement on the model needs to be carried out, as well as the development of other sub-systems models.

More realistic model, involving more accurate quantitative representation (mathematical model) of each subsystems of the platform may improve the quality and performance of the developed platform.

\section{References}

[1] Ian Moir, Allan Seabridge, Aircraft Systems: Mechanical, electrical, and avionics subsystems integration, John Wiley \& Sons, England, 2007

[2] R.F. Stengel, Flight Dynamics, Princeton University Press, New Jersey, 2004

[3] M.V. Cook, Flight Dynamics Principles, Elsevier, Oxford, USA, 2007

[4] Peter H. Zipfel, Modeling and Simulation of Aerospace Vehicle Dynamics, AIAA Education Series, Virginia, 2007

[5] http://en.wikipedia.org/wiki/Flight_sim ulator 
[6] David Allerton, Principles of Flight Simulation, John Wiley \& Sons, United Kingdom, 2009

[7] http://www.cae.com/

[8] http://www.sim-industries.com/

[9] Harry Saktian Nugraha and Rianto Adhy Sasongko, The Development of a Computer Simulation Platform for Evaluating Mission Performance of a Low-cost UAV, Regional Conference on Mechanical and Aerospace Technology, Bali, February 9 - 10, 2010
[10] R.A. Sasongko, J. Sembiring, and H. Muhammad, Design and Development of Unmanned Aerial Vehicle Mission Simulator for Pre-Implementation Performance Test of the Autonomous Control System, $3^{\text {rd }}$ Regional Conference on Mechanical and Aerospace Technology, Manila, Philippines, March 4-5, 2011

[11] MATLAB/Simulink User Manual, Mathworks Inc. 